science and technology. The second part consists of the "sources" already mentioned, which are claimed to show that modern science started with an awareness of the limitations of its scope, passed through a phase in which it forgot its own limitations, and is now appreciating these limitations with new insight. The first of Schrödinger's books is a re-issue, with one addition, of the essays previously published in "Science and the Human Temperament" (1935). His second book consists of the Tarner Lectures for 1956 . It is the most far-ranging of all these books and, in one way or another, bears upon the whole range of human thought. To the reviewer it breathes a freer air than do the others. This is perhaps because Schrödinger seems less prone to regard recent developments as supremely decisive in the long roll of man's thinking and so it comes more naturally to him to look beyond them. Whereas Heisenberg says, "When we speak of the picture of nature in the exact science of our age, we do not mean a picture of nature so much as a picture of our relationships with nature", Schrödinger says, "The world is given to me only once, not one existing and one perceived. Subject and object are only one. The barrier between them eannot be said to have broken down as a result of recent experience in the physical sciences, for this barrier does not exist".

However, when these distinguished authors stand back to survey the whole realm of thought, it cannot $b e$ expected of the writer of a short review to stand even farther back to survey the survey. All he can do is to urge others to enjoy the extraordinary richness of thought contained in each of these brief volumes.

\section{W. H. MaCrea}

\section{ADVANCES IN MICROBIOLOGY}

\section{Annual Review of Microbiology}

Vol. 12. Edited by Charles E. Clifton in association with Sidney Raffel and Mortimer P. Starr. Pp. viii + 579. (Palo Alto, Calif.: Annual Reviews, Inc., 1958.) 7 dollars.

$\mathrm{N}$ these days when the expanding volume of literature Is the despair of every scientist who hopes to keep abreast of advance in anything more than a narrow field, the annual review volumes have become indispensable. They serve two purposes : to provide a rapid guide to recent literature and, more rarely, to present an appreciation and synthesis of recently acquired knowledge. The latter type of review article is only possible when knowledge in a particular branch has reached a degree of attainment and significance that enables something more than appraisal of detail to be attempted. Three of the major articles in the present "Annual Review of Microbiology" are in this latter class and each makes a valuable contribution in its own right: "Metabolism of Carbohydrates and Related Compounds" by S. R. Elsden and J. L. Peel is an outstanding contribution, particularly in its consideration of the energetics of anaerobic metabolism, discussing the breakdown of substrates from the point of view of the yield of adenosine triphosphate. The article also covers cellulose synthesis and breakdown, the breakdown of aromatic compounds, and tricarboxylic acid eycles. "Bacterial Geneties" by A. W. Ravin reviews advances on the mutation, replication, transfer and function of genetic material, and the contribution by $\mathrm{A}$. Nason and H. Takahashi places recent studies on denitrification, nitrate utilization, nitrification and nitrogen fixation into perspective in the field of "Inorganic Nitrogen Metabolism".

"Bacterial Protoplasts" and "Bacterial Viruses" are dealt with by C. Weibull and W. Weidel, respectively, while L. Provasoli presents a thoughtful study of the relation between laboratory and field investigations in the "Nutrition and Ecology of Protozoa and Algae". The parasitic and pathogenicity aspects of microbiology are well catered for in this volume, which contains reviews on staphylococei, respiratory tract viruses, virus infection in plants, parasitic diseases in man, and the use of bacteria grown in vivo for studies on the basis of their pathogenicity. The control of infection is discussed in articles on antibiotics in plant disease, chemical disinfectants, and radiation preservation of food. P. Grabar provides a further summary, with 200 references, of recent Russian literature.

It can be seen that the present volume, containing nineteen articles and a grand total of 3,211 references, will find a place on the shelves of microbiologists, medical men and biochemists, all of whom will acknowledge their indebtedness to the editors and contributors for maintaining the high standard that we have come to expect of these "Annual Reviews".

\section{TOPICS IN CARBOHYDRATE CHEMISTRY}

\section{Polysaccharides in Biology}

Transactions of the Second Conference, April 25, 26 and 27, 1956, Princeton, N.J. Edited by Dr. George F. Springer. Pp. 245. (New York: Josiah Macy, Jr. Foundation, 1957.) 5 dollars.

7 HIS book gives a verbatim account of the trans. actions of a second conference, sponsored by the Josiah Macy, Jr. Foundation. It brought together a group of experts who discussed three topics in carbohydrate chemistry, namely: "Sialic Acid and Related Compounds"; "Interaction of Polysaccharides and Viruses"; and "Pyrogens". These topics are of the utmost importance in certain aspects of medicine at the present time, and the twenty-six experts were undoubtedly among the best that could be got together for the particular subjects. The method of reporting the conference, however, must be sharply criticized, because it can only be of value to the expert: even to the expert it is very irritating, but to the non-specialist it would be almost impossible to get anything of real significance out of the book. The whole thing is reported in a completely uncritical manner, and many comments of the experts, some of them mere interjections, are of no value. Perhaps the scientific editors will in future take a leaf out of the books of the Ciba Foundation and provide a substantial piece of wellthought-out writing on which to base the main conclusions of a topic: then comments by partieipants in the succeeding discussion will have more weight and will be more tangible.

The discussion on sialic acid and related compounds was led by Dr. F. Zilliken, and generally all that is known about this interesting group of substances up to 1956 was brought out either by direct communication or by discussion. The growing importance of this nonosaminic acid was well illus- 